\title{
De Brasília à Caracas: Cooperação Brasileira para Contenção Venezuelana
}

\author{
Octavio Ribeiro ${ }^{1}$; Pedro Maia $^{2}$
}

\section{Resumo}

O ano de 2012 entra para a história do sistema institucional sul-americano e caribenho, sendo a inserção da Venezuela no Mercado Comum do Sul representação da intensificação de tal processo integracional. Ao entrar como membro pleno do MERCOSUL, a Venezuela se vê inserida em três dos principais processos de integração regionais propostos e liderados pelo Brasil, sendo os outros dois a União das Nações SulAmericanas (UNASUL) e a Comunidade dos Estados Latino-Americanos e Caribenhos (CELAC). Este artigo visa compreender os motivos pelos quais o Brasil estimula a entrada venezuelana em tais instituições, com base analítica no neorrealismo defensivo de Joseph Grieco, que permite uma análise de instituições sem que se configure um perigo ao núcleo duro do projeto de pesquisa neorrealista. Percebe-se que em cada instituição, o Brasil desenvolve uma maneira particular para minar a atuação venezuelana no sistema regional.

Palavras-chave: Brasil e Venezuela, neorrealismo defensivo, integração regional, arranjos institucionais, contenção.

\section{Abstract}

The year of 2012 became a remarkable year for the Latin America and Caribbean's institutional system. The insertion of Venezuela in MERCOSUR represents the intensification of this process of integration. Once in MERCOSUR, Venezuela becomes member of three of the most relevant process of regional integration, UNASUR, MERCOSUR and CELAC, all of them led by Brazil. This article aims to understand the reasons why Brazil fosters Venezuela's entrance in those institutions, based at Grieco's defensive neo-realism, which allows us to analyses the institutional process without harming neorealism's hardcore and it's research program. It can be seen that in each institution Brazil develops a particular way to undermine Venezuelan's regional project.

Key Words: Brazil and Venezuela, defensive neorealism, regional integration, institutional arrangements, contention.

\section{Abstracto}

\footnotetext{
${ }^{1}$ Graduando em Relações Internacionais pela PUC-Rio e estagiário do BRICS Policy Center, no núcleo Country Desks, trabalhando com Rússia. E-mail: octavio.mainenti@yahoo.com

${ }^{2}$ Graduando em Relações Internacionais pela PUC-Rio e pesquisador bolsista do Programa de Educação Tutorial (PET). E-mail: pedrodsmaia@gmail.com
} 
El año 2012 llega a la historia del sistema institucional de América del Sur y el Caribe, con la inclusión de Venezuela en el Mercado Común del Sur representando la intensificación de este proceso integracional. En su calidad de miembro pleno del MERCOSUR, Venezuela se encuentra inserta en tres grandes procesos de integración regionales propuestos y liderados por Brasil, los otros dos son la Unión de Naciones Suramericanas (UNASUR) y la Comunidad de Estados de América Latina y el Caribe (CELAC). Este artículo tiene como objetivo comprender las razones por las cuales Brasil estimula la entrada de Venezuela en esas instituciones, con base en análisis neorrealista defensiva de Joseph Grieco, lo que permite un análisis de las instituciones sin ser un peligro para la configuración del núcleo duro del proyecto neorrealista de investigación. Se observa que en todas las instituciones, Brasil desarrolla una manera particular para socavar las operaciones en Venezuela en el sistema regional.

Pallabras Clave: Brasil y Venezuela, el neorrealismo defensivo, la integración regional, los acuerdos institucionales, la contención. 


\section{Introdução}

No decorrer de 2012, uma série de eventos marcou a história do sistema político latino-americano. Entre esse eventos podemos mencionar a suspensão do Paraguai do Mercado Comum do Sul (MERCOSUL), devido ao descumprimento da cláusula democrática. Todavia, também foi possível notar a presença de processos de integração regionais mais profundos e altamente institucionalizados, sendo a inserção da Venezuela como membro pleno do MERCOSUL uma evidência de tal afirmação. O ingresso deste demonstra o ápice do processo integracional na América Latina, paralelo a um maior grau de institucionalidade através do pleno funcionamento da União das Nações SulAmericanas (UNASUL) e as primeiras conformações acerca da Comunidade dos Estados Latino-Americanos e Caribenhos (CELAC). Dentro de tal cenário, se torna nítida a atuação da Venezuela. Através da sua inserção em tais arranjos, o Estado venezuelano busca ganhar mais voz e exercer maior influencia dentro do jogo politico regional.

Não obstante a criação de tais instituições, observa-se políticas externas divergentes de Brasil e Venezuela, principalmente em relação aos projetos regionais do mandatário venezuelano Hugo Chávez, de caráter de esquerda exacerbada, agressivo e baseada no petróleo como instrumento de barganha em nível multilateral (Arellano, 2009, p. 131-133). Ao passo que a política regional brasileira é baseada no comércio como forma de se racionalizar poder, angariar parceiros de cooperação e exercer influência no espaço latino-americano (Arellano, 2009, p. 124-127). Dessa forma, buscamos compreender o porquê - apesar das divergências - do Brasil apoiar a adesão venezuelana a arranjos institucionais, como MERCOSUL, UNASUL e CELAC.

A partir desse ponto, recorremos ao arcabouço teórico criado por Grieco, em The Maastricht Treaty, Economic and Monetary and the New-realist Research Program, para 
maiores entendimentos. Analisando a posição do Brasil de acordo com este arcabouço, percebemos que o Brasil visa consolidar sua liderança regional, melhorar sua posição relativa em meio ao Sistema Internacional e perpetrar a eterna busca realista por segurança. Para tal, conforma a Venezuela em arranjos institucionais, tais quais MERCOSUL, UNASUL e CELAC, restringindo seu comportamento e tornando-o mais previsível (Grieco, 1997, p. 163).

A instrumentalização de arranjos institucionais pelo Brasil, se dá na tentativa brasileira de racionalizar o uso de poder, como forma de manutenção de sua posição relativa superior. Dada a ativa participação brasileira em organizações regionais, inserir a Venezuela em tais espaços significa: (1) impor ao estado venezuelano uma série de determinações que viriam a restringir institucionalmente a sua atuação e gerar previsibilidade quanto ao seu comportamento - como a cláusula democrática; (2) inserir um novo ator em contextos onde o Brasil já possui uma maior influência, como o MERCOSUL; (3) conter a atuação venezuelana e suas pretensões regionais ameaçadoras frente o projeto regional brasileiro.

O MERCOSUL se trata de uma união aduaneira inicialmente idealizada bilateralmente entre Brasil e Argentina, que se estendeu a Paraguai, Uruguai e, recentemente, Venezuela - arquitetado para promover o desenvolvimento econômico e social com equidade, combate à pobreza e respeito à democracia (Prado, 1997, p. 276299). A partir da criação do MERCOSUL, temos configurada uma participação brasileira mais ativa, em busca de uma liderança regional, tanto econômica quanto política (Arellano, 2009, p. 127). Em junho de 2012, o Mercado Comum do Sul, engloba mais um Estado-membro: a Venezuela de Hugo Chávez, após seis anos da assinatura do Protocolo de Adesão ao bloco por parte desta. 
A UNASUL, advinda da CASA (Comunidade Sul-Americana de Nações), tratase de uma organização intergovernamental, sem pretensões supranacionais. A instituição foi idealizada na tentativa de se criar um espaço para o regionalismo latino-americano que não tivesse a participação direta dos EUA. Justamente por tal objetivo, que o Estado brasileiro se torna um dos principais apoiadores da instituição. Em tal organização, o Brasil vem exercendo democrática liderança na medida em que estimula o fortalecimento da própria instituição e das instituições multilaterais da região (Saraiva, 2010, p. 151168).

A CELAC está longe de ser uma iniciativa isolada, trata-se de uma continuação de parte do processo de cercamento regional consolidado nos últimos anos, sendo amplamente coordenado pelo Brasil, que vê nesta instituição um possível instrumento de ampliação do diálogo político. Esta tem como principal desafio buscar determinada coordenação política, posições comuns para lidar com problemas comuns e diminuir suas dificuldades de se relacionar com outros países (Vaz, 2010, p. 4-8). A CELAC assume patrimônio histórico do Grupo do Rio e da CALC (Cúpula da América Latina e do Caribe $)^{3}$

No decorrer dessa análise, tentaremos, a partir do estudo das avaliações de autores como Félix Arellano, Sean Burges e Míriam Saraiva e baseados teoricamente por Joseph Grieco e Lloyd Gruber, evidenciar os motivos pelos quais o Brasil conforma arranjos institucionais e o desejo pela adesão da Venezuela nos mesmos.

\footnotetext{
${ }^{3} \mathrm{O}$ Grupo do Rio era um instrumento de concertação política destinado à democracia, inspirado nos trabalhos desenvolvidos pelos Grupos de Contadora e de Apoio em favor da paz na América Central. Já a Cúpula da América Latina e do Caribe sobre Integração e Desenvolvimento (CALC) tinha como objetivo tratar de atitudes competentes nas áreas de integração regional, cooperação e do, desenvolvimento sustentável, erradicação da pobreza, promoção da justiça social e da democracia (Itamaraty, 2014).
} 
A abordagem de Chávez é marcada por um viés estatista e mercantilista que pretende ampliar a riqueza do país através da exploração do petróleo, Burges argumenta que tal via tende a criar uma visão de globalização centrada na Venezuela, assim como um projeto regional (Burges, 2007, p.1-6). Partimos de tal pressuposto para fundamentar o argumento de que tal busca de poder cria uma ameaça à posição brasileira no sistema, justificando o incentivo brasileiro à entrada da Venezuela em arranjos institucionais.

Félix Arellano afirma que, ainda que Brasil e Venezuela corroborem em uma ideologia política esquerdista, existem diferenças tanto em profundidade ideológica Brasil sendo centro-esquerdista, enquanto Venezuela se mantendo como uma esquerda radical - quanto entre os projetos regionais dos dois Estados: Brasil adota uma política comercialista e Venezuela pauta sua política externa no pilar energético, principalmente através do petróleo (Arellano, 2009, p. 124-127). Procuramos utilizar tal argumento para fundamentar nossa hipótese de que, devido ao posicionamento relativo superior brasileiro e graças a projetos regionais divergentes, o Brasil apoia a adesão da Venezuela a arranjos regionais como uma forma de racionalização de poder.

Apesar dessa divergência política - tanto quanto ao aspecto político-ideológico dos governos, quanto aos projetos regionais -, Ruiz e Saraiva afirmam que a Venezuela, se aproximava cada vez mais do MERCOSUL, ao passo que se afastava da Comunidade Andina. Todavia, não percebia que tal aproximação, levava a Venezuela cada vez mais para dentro do jogo político brasileiro da autonomia pela integração. Tal estratégia de política externa é a responsável por uma liderança regional discreta por parte do Brasil (Ruiz e Saraiva, 2009, p. 124-127). Logo, esse entendimento das dinâmicas politicas regionais acaba por corroborar com o nosso argumento, de que o Brasil vale-se de instituições para manter sua posição defensiva no sistema. 
Baseando-se na abordagem de Gruber ${ }^{4}$, percebemos que a escolha das instituições se faz presente uma vez que estas formalizam termos de cooperação, monitoram comportamento e transmitem informações de maneira eficientes e menos custosa. Assim sendo, quando o Brasil deseja alterar o comportamento da Venezuela é muito mais provável que isso ocorra de maneira velada, indireta, envolvendo a manipulação das opções de escolhas deste. Se tratando de uma tática indireta de atuação, as restrições à Venezuela aparecem disfarçadas de condicionalidades institucionais, logo, o Estado venezuelano acaba tendo seu escopo de atuação limitado. Esta ação brasileira emerge como racional, na medida em que se toma um caminho menos custoso para combater a política externa venezuelana, discordante da brasileira (Gruber, 2005, p. 103-108).

O tema se mostra relevante para as R.I.s por demonstrar duas possibilidades de análise do estudo: uma analítica e outra prática. A analítica se dá através do marco teórico, o realismo, que neste artigo partirá de pressupostos como a anarquia internacional, o posicionamento dos Estados em meio ao Sistema Internacional e o impacto deste na formação de preferências dos atores envolvidos e a racionalização de custos (Grieco, 1997, p. 163-179), se relacionando diretamente com nosso objetivo de análise. A prática por lidarmos com: (1) os processos de integração nas Américas - área de intenso dinamismo no que diz ao tema; (2) atores de peso em nível regional - Brasil e Venezuela, o primeiro em busca de um papel mais vultoso na região; (3) um ator deveras polêmico como a Venezuela e seu mandatário ainda mais, Hugo Chávez.

Nossa metodologia se baseia em uma análise teórico-empírica. Usamos um embasamento teórico e complemento de dados empíricos. Nossa pesquisa é baseada em

\footnotetext{
${ }^{4}$ Tem como objetivo entender o porque de certos arranjos institucionais possuírem normas flexíveis. Afirma então que a flexibilidade é importante, uma vez que permite a inserção de novos atores e uma reformulação das normas do regime e de sua agenda (Gruber, 2005).
} 
um rastreamento de processo, na medida em que rastreamos e traçamos o comportamento do Brasil no MERCOSUL, UNASUL e CELAC. Tomamos como variável independente a posição relativa dos Estados do Brasil e Venezuela e como variável dependente a intensificação da cooperação entre os supracitados. Dessa forma, enquadramos a cooperação entre os dois Estados em função da posição que os mesmos ocupam no contexto internacional.

O marco teórico selecionado foi o neorrealismo defensivo, que analisará a formação de preferência e o comportamento dos Estados no Sistema Internacional. Tendo as capacidades relativas como referencial, os Estados passam a seguir determinadas linhas de comportamento, tomando atitudes defensivas em decorrência da constante insegurança inerente a um mundo anárquico Os principais atores do Sistema Internacional agem no sentido de promover segurança e pleitear uma redução das suas ameaças, mantendo suas posições relativas e, por consequência, sua segurança propriamente dita. Deste modo, é cabível a criação de instituições que visem uma racionalização do poder (Grieco, 1997, p. 161-178).

Nossa abordagem técnica, contudo, vai além do neorrealismo propriamente dito. De acordo com Lakatos, um programa científico ao longo do tempo não se deve basear em uma teoria fixa e imutável, e sim num programa evolutivo. Um programa de pesquisa deve conter: (1) um núcleo duro composto de conceitos fixos; (2) certas premissas sobre o campo determinado e (3) um protective belt (um cinturão de proteção) - composto de hipóteses auxiliares que derivam do mesmo núcleo. O neorrealismo possui como núcleo duro: (1) Estados como os principais atores do Sistema Internacional; (2) Estados estes substantivamente e instrumentalmente racionais; (3) as preferências e escolhas destes são moldadas pela Anarquia Internacional. Os Estados estão, majoritariamente, interessados 
em segurança e independência, o que os tornam sensíveis aos custos e, por consequência, pendendo para escolhas políticas que visem promover tais interesses (Grieco, 1995, p. 26-27).

Baseado nesse desenho de pesquisa, o neorrealismo nos oferece inúmeras hipóteses quanto a temática da cooperação e instituições internacionais. Mesmo com a descrença neorrealista em instituições, se faz necessário levar em conta que, em muitas das vezes, a racionalidade dos Estados leva-os a aceitar a importância das instituições internacionais. Deste modo, os teóricos neorrealistas deveriam olhar para hipóteses auxiliares até então negligenciadas (Grieco, 1995, p. 28-30).

Mas além disso, pretendemos debater o alcance teórico neorrealista em lidar com questões políticas que vão além das grandes potências. Nesse sentido, afirmamos que pensar em um realismo para Estados localizados em espaços ditos "não-centrais" do Sistema Internacional envolve analisar elementos que não são necessariamente entendidos em termos de poder concreto pelas grandes potências. Logo, se faz necessário focar em aspectos políticos ausentes, em grande parte do tempo, nos cálculos de poder, como as instituições internacionais, relações regionais e fluxos econômicos. O entendimento realista de poder em termos tangíveis é informado, majoritariamente, por um entendimento das grandes potências. Estados que não se encontram no seleto grupo das potências, acabam utilizando outros elementos para exercer influência - como relações comerciais - que apesar de não serem necessariamente concretos, acabam interferindo diretamente nas relações de poder entre os Estados.

\section{Marco Teórico}


O recente debate sobre instituições, dentro do campo de RI, travado entre o neorrealismo e o neoliberalismo institucional servirá como introdução ao nosso marco teórico. O neorrealismo possui um núcleo duro composto de três suposições: (1) os Estados são os principais atores na politica internacional; (2) são atores racionais; (3) suas preferências e escolhas são determinadas pela ausência de uma autoridade internacional centralizada. O neorrealismo sugere que a anarquia internacional força os Estados a se preocuparem com sua independência e segurança, se tornando sensíveis aos custos e como consequência, escolhendo políticas que os auxiliem a promover sua segurança e autonomia, focando nos ganhos relativos ${ }^{5}$. Dessa forma, a cooperação entre os Estados e as instituições internacionais emergem apenas como meros instrumentos das relações de poder entre os Estados (Waltz, 1979).

O neoliberalismo, por sua vez, concorda com certos conceitos presentes no neorrealismo, como a racionalidade do ator estatal, seu papel de protagonismo no Sistema Internacional e o entendimento do âmbito internacional como anárquico. Não obstante, uma discordância entre ambas correntes teóricas está diretamente relacionada ao aspecto da cooperação. Para os neoliberais, os arranjos de cooperação aparecem como um mecanismo encontrado entre os Estados de conseguir mitigar os efeitos da anarquia, uma vez que as instituições são capazes de oferecer maior informação, redução dos custos de transação e previsibilidade quanto as ações de outros Estados (Keohane, 1984).

Dessa forma, notamos como que ambas vertentes teóricas acabam se aproximando em certos pontos - como a racionalidade estatal - mas diferindo no trato com as instituições. Todavia, mesmo dentro da categoria mais ampla de neorrealismo passam a surgir distinções. A principal delas é entre o neorrealismo ofensivo e o neorrealismo

\footnotetext{
${ }^{5}$ Os ganhos relativos se tornam importantes, na medida que qualquer assimetria de ganho pode ser revertida em uma assimetria de poder concreto.
} 
defensivo. O primeiro acredita que o objetivo de todos os Estados é a hegemonia e que o principio definidor de uma potência é seu aparato militar. Isso se dá graças à anarquia do Sistema Internacional, que força os Estados a tomarem posturas agressivas em prol da sobrevivência (Mearsheimer, 2003) ${ }^{6}$. Já o neorrealismo defensivo - nesse trabalho representado pelas ideias de Grieco - afirma que os Estados, no sistema internacional, estão em busca de segurança e, para alcançar tal objetivo, é necessário adotar uma postura defensiva. Dessa forma, as instituições podem servir como instrumentos de projeção de poder, por se tratarem de arranjos capazes de otimizar as relações e aprimorar o balanço entre custo e beneficio de seus Estados membros. (Grieco, 1995, p. 27).

O neorrealismo de Grieco permite que as instituições internacionais tenham um papel de relevância para os Estados, na medida em que as mesmas se tornam arenas para a projeção de poder e aprimoramento da posição relativa dos Estados. Além disso, as organizações são capazes de potencializar o uso do poder graças a seus instrumentos de provisão de previsibilidade, redução de incertezas e ampliação da sombra do futuro. Em linhas gerais, afirmamos que tal tática significa empregar poder em um ambiente seguro (Grieco, 1995).

Ao pensar em um debate com liberais, nesse caso Lisa Martin, notamos como a mesma afirma que as instituições se tornam um espaço de atuação secundário para Estados que não possuem capacidades, usando regimes e arranjos multilaterais como alternativa na busca de uma melhor posição no cenário internacional e de lucro (Martin, 1992). Contudo, o que afirmamos com Grieco, é que as instituições estão diretamente relacionadas aos cálculos de poder e as capacidades. Não se trata de espaços secundários onde apenas Estados sem capacidades estão presentes, trata-se, na verdade, de espaços

\footnotetext{
${ }^{6}$ Mearsheimer é considerado um dos responsáveis por difundir o chamado neorrealismo ofensivo.
} 
seguros de uso do poder, onde o mesmo é racionalizado e as chances de ampliação dos lucros e otimização da posição do Estado no Sistema Internacional são concretas (Grieco, 1995).

Dessa maneira, percebemos como o neorrealismo pode dar luz a outras hipóteses, até então marginalizadas, permitindo uma atualização teórica que respeita o núcleo duro dessa corrente e a torna mais flexível, contribuindo para a renovação de tal lente de análise.

\section{Políticas Externas Divergentes de Brasil e Venezuela}

O projeto regional venezuelano é de caráter geoestratégico e militar, vem encarregado de elementos ideológicos claramente percebidos na política externa chavista. Através de uma política externa pautada no uso de recursos energéticos, como na notável Petrocaribe, procura-se o fortalecimento de sua liderança tanto no continente latinoamericano como no da América Central. Ao mesmo tempo, a Venezuela assume um papel mais relevante através de alianças com Irã, Rússia e China e a instrumentalização da OPEP como fórum de incidência mundial. Em contrapartida, o projeto regional brasileiro é multidimensional e se norteia através do desenvolvimento produtivo, industrial e comercial (Serbin, 2009, p. 147-148).

Ambos os projetos não excluem as relações com os EUA, mas as consideram a partir de distintas perspectivas. A Venezuela adota postura conflitante frente aos EUA, enquanto que o Brasil, ao pesar o valor comercial de uma relação com os estadunidenses, busca ser reconhecido com o interlocutor de uma relação que não ameaça suas aspirações regionais. Ambas as estratégias, ainda que distintas, correspondem a uma visão multipolar de mundo. Os contrastes são marcados por visões divergentes: enquanto uma 
é composta por um viés militar munido de forte apelação ideológica, a outra é definida pelo desenvolvimento econômico que faz parte de uma estratégia diplomática (Serbin, 2009, p. 148-150). Além destas divergências frente aos EUA, é evidente o desacordo dos Brasil e Venezuela com relação às orientações estratégicas para a fomentação de uma governabilidade no contexto internacional (Arellano, 2009, p. 131).

\section{Mercado Comum do Sul (MERCOSUL)}

Após 50 anos do tratado idealizado pelos ministros das Relações Exteriores Oswaldo Aranha (Brasil) e Enrique Ruiz-Guiñazú (Argentina), que ambicionava a criação de uma instituição que provesse um intercâmbio livre, convertendo-se gradualmente em uma união aduaneira, Brasil e Argentina efetivam tais pretensões integracionais, incorporando as Repúblicas do Uruguai e do Paraguai, ao celebrar o Tratado de Assunção (1991) fundando, portanto, o Mercado Comum do Sul (MERCOSUL). A arquitetura do bloco sofreu atenuante mudança em 2012, com a suspensão do Paraguai, uma vez que este rompe com as cláusulas democráticas previstas no Protocolo de Ushuaia (1998), e a adesão da Venezuela (Bandeira, 2005).

O MERCOSUL é marcado pelo regionalismo aberto ${ }^{7}$, visando à extensão do comércio entre seus membros-plenos, membros-associados e países terceiros. Com base no Protocolo de Ouro Preto (1994), destacamos do bloco três pilares institucionais: (1) o Conselho do Mercado Comum - que visa à adoção de decisões quanto à política do bloco, tal qual a eliminação de instrumentos e adoção de políticas em determinada área; (2) o Grupo Mercado Comum - que ambiciona um auxílio ao CMC em decisões de caráter

\footnotetext{
${ }^{7}$ Regionalismo aberto trata não só da expansão comercial intrazona, mas também da ampliação das trocas com terceiros países (Itamaraty, 2014).
} 
executivo e (3) a Comissão de Comércio do MERCOSUL - órgão técnico responsável por apoiar o bloco no que tange políticas comerciais.

Para o Brasil, o projeto do MERCOSUL vem como uma maneira de criar um sistema regional mais previsível e estável, uma vez que se cria uma zona de paz e relativa cooperação entre seus Estados-membros e uma possibilidade de convergência em nível político do bloco com relação a outras instituições. O Brasil tem interesse em projetar sua imagem de liderança política em nível regional e, ainda que não seja uma pretensão hegemônica, se tornar o país referência do bloco aos olhos do Sistema Internacional (Vigevani e Ramanzini, 2011). Importante ressaltar que o MERCOSUL vem como o primeiro bloco econômico proposto pelo Brasil que serviria como mecanismo fortalecedor de sua posição relativa em fóruns multilaterais, permitindo uma racionalização de poder e uma partilha de gastos (Grieco, 1997). Em âmbito econômico, o MERCOSUL é uma alternativa brasileira para a expansão das oportunidades de mercado, das relações de complementaridades das economias-membras por meio da redução das barreiras alfandegárias e uma alavanca negociadora, ao passo que funciona como mecanismo de barganha com outras instituições internacionais.

Como já dito, em 2012 o MERCOSUL passa por um período de mudanças a partir do golpe do Senado Paraguaio para com o então Presidente Fernando Lugo, que culminou na sua suspensão nas três principais instituições das quais fazia parte em nível regional (MERCOSUL, UNASUL e CELAC), devido à infração das cláusulas democráticas positivadas em textos jurídicos destas; e a adesão da Venezuela ao bloco, após seis anos da aprovação do seu pedido de adesão neste. Pode-se relacionar diretamente o primeiro fenômeno com o segundo, uma vez que o Paraguai era o último Estado-membro do MERCOSUL a deixar em pendência o ingresso da Venezuela no mesmo. Pode-se afirmar 
que os receios quanto ao cumprimento das cláusulas democráticas e quanto a acordos comerciais por parte da Venezuela, somados ao alto grau de imprevisibilidade das ações venezuelanas foram motivos pelo longo processo de tramitação da adesão desta em meio ao Senado paraguaio. A partir do momento em que o Paraguai se encontra suspenso, seu poder de decisão e veto quanto a assuntos pertinentes ao bloco também estão sob suspensão, sendo possível acelerar o processo de entrada da Venezuela no bloco (CEBRI, 2012).

As percepções venezuelanas sobre a integração regional são bem diferentes das brasileiras, e sua recente adesão ao MERCOSUL é resultado de um processo iniciado nos anos 90. Até 2002, não havia posição predominante no desenho da política externa chavista quanto os processos de integração regional, principalmente o MERCOSUL. Com o afastamento definitivo da Venezuela dos Estados Unidos, devido a divergências políticas, no ano de 2003, a estratégia venezuelana de integração torna-se clara já no ano seguinte. A ascensão de governos de centro-esquerda no Brasil, na Argentina e no Uruguai e a decisão dos países andinos de negociar bilateralmente com os EUA, culminaram na saída da Venezuela da Comunidade Andina de Nações e consequentemente na intensificação do processo de integração, culminando com a solicitação de sua entrada como membro pleno do MERCOSUL. Após a vitória de Chávez no Referendo Constitucional de 2009, tem-se configurada uma nova etapa de política exterior venezuelana, onde fatores fizeram com que privilegiassem a dimensão política dos processos de integração, visando criar um bloco que assegura aos países sulamericanos poder, autonomia, segurança e influência nos cenários globais (Saraiva e Ruiz, 2009, p. 157-161). 
O Brasil teve importante aporte no processo de aceleração da entrada da Venezuela no bloco. Apesar de visões e narrativas diferentes frente à região, o Brasil enxergou neste movimento uma possibilidade de se confrontar outro poder regional emergente (Serbin, 2009, p. 146-149). As amarras institucionais do MERCOSUL conseguiriam moldar o comportamento de um Estado com enorme peso econômico devido as suas reservas energéticas, a Venezuela fica, desta forma, sujeita a elementos de contenção. Em sua essência, o Mercado Comum do Sul é parte da estratégia brasileira de transformação do bloco mediante a integração dos Estados-membros da Comunidade Andina de Nações (CAN) em um núcleo duro da integração sul-americana. Cabe mencionar que o MERCOSUL é altamente reflexivo do posicionamento da política externa brasileira, de seu viés comercialista e produtivo (Vigevani e Ramanzini, 2011). Desta maneira, a partir do momento em que a Venezuela integra o bloco, ela passa a se inserir de maneira indireta na política externa brasileira, permitindo a República Federativa do Brasil racionalizar o uso do poder assim como os custos de contenção de um projeto regional concorrente (Grieco, 1997).

Cabe mencionar que as relações comerciais entre Brasil e Venezuela, sempre foram marcadas por uma dependência venezuelana, uma vez que grande parte da pauta de exportação venezuelana é destinada ao Brasil, porém a reciproca não é verdadeira, já que o Brasil possui uma pauta de exportação mais diversificada, tanto no âmbito de produtos quanto no âmbito de parceiros (Câmara de Comércio Brasil e Venezuela, 2011). Outro fato que demonstra a dependência venezuelana é o padrão de comércio entre Brasil e Venezuela, onde o primeiro exporta principalmente bens de capitais e automóveis, ao passo que a Venezuela exporta sardinha e derivados de petróleo (Câmara de Comércio Brasil e Venezuela, 2011). Dessa forma, argumentamos que ao a Venezuela ingressar no 
MERCOSUL, tais laços econômicos tendem a se intensificar, assim como a relação de dependência venezuelana do Brasil. Todavia, em um ambiente institucionalizado, o Brasil consegue racionalizar poder, assim como os custos do comércio (Grieco, 1997). Em síntese, o Brasil continua se posicionando de maneira defensiva, racionalizando poder e contendo a atuação venezuelana na região.

\section{União das Nações Sul-Americanas (UNASUL)}

A União das Nações Sul-Americanas é composta pelos 12 países da América do Sul. É o resultado de um projeto ambicioso iniciado em dezembro de 2004, na Cúpula de Cuzco, quando se celebrava o $180^{\circ}$ aniversário da batalha que consolidou o fim do processo de independência da América Espanhola. Em Cuzco, no Peru, temos conformada a base institucional da antecessora da UNASUL, a CASA (Comunidade das Nações Sul-Americanas), para seu principal promotor, e ex-presidente argentino Duhalde, este foi um passo histórico, por marcou a retomada do sonho dos libertadores (Marchiori, 2011, p. 162).

A CASA tinha como interesse inicial fazer frente à União Européia, visando à criação de um livre comércio e cooperação na área de defesa. Também previa continuação do contexto da integração na área de infraestrutura. Tal integração ocorreria de maneira gradual, a partir da concordância e convergência dos compromissos econômicos, políticos e jurídicos assumidos previamente em outros arranjos institucionais, como a Comunidade Andina de Nações (CAN) e o Mercado Comum do Sul (MERCOSUL). A CASA seguia os moldes econômicos previstos na antiga ALALC (Associação LatinoAmericana de Livre Comércio), à medida em que previa uma criação de uma zona de livre comércio, e os moldes institucionais da ALADI (Associação Latino-Americana de 
Integração). Em suma, a CASA vinha para preencher uma lacuna em termos de articulação política no continente latino-americano como um todo (Marchiori, 2011, p. 163-168).

Podemos perceber que dada a condição dos Estados ao adotar um posicionamento defensivo e estarem constantemente preocupados com o poder relativo, muitas vezes estes escolhem ingressar em arranjos regionais como uma forma de manterem sua atual posição, oriunda de sua quantidade de poder relativo, auxiliando também na manutenção de sua segurança (Grieco, 1997, p.166-168).

A estrutura institucional da CASA é solidificada em 2005, na reunião de Brasília, e em 2007 propõe-se uma mudança de nome: de CASA para o atual UNASUL. Ao ser aprovada essa mudança nominal, a UNASUL passa a existir quanto instituição, assim, ganha legitimidade jurídica. Concomitantemente à mudança nominal, vêm propostas ainda mais ambiciosas do que as previstas em Cuzco, tais quais: a criação de um banco para o desenvolvimento dos Estados-membro (Banco do Sul), um parlamento (Parlamento Sul-Americano), e um Conselho de Defesa.

É de competência da UNASUL: (1) a criação de um espaço de articulação no âmbito social, cultural, econômico e político entre seus povos; (2) priorizar o diálogo, as políticas sociais, a educação, a energia, a infraestrutura, o financiamento e o meio ambiente, entre outros, com vistas a criar a paz e a segurança; (3) eliminar a desigualdade socioeconômica, alcançar a inclusão social e a participação cidadã; (4) fortalecer a democracia e reduzir as assimetrias no marco do fortalecimento da soberania e independência dos Estados. Também está em sua pauta o debate acerca da defesa do território, bem como a proteção de suas fronteiras, a fomentação de uma estratégia comum para todos os Estados-membros. 
Pode-se dizer que a UNASUL, ou ao menos seu esqueleto, foi uma iniciativa brasileira que visava aprofundar os laços políticos e militares entre os Estados sulamericanos. Importante ressaltar a existência de uma distribuição de capabilities mais igualitária em comparação com outros blocos regionais (Flemes, 2008, p. 15-16). Apesar de a instituição ter sido inicialmente idealizada pelo Brasil, fica claro que, para os Estados mais frágeis, a instituição se torna proveitosa na medida em que os oferece a oportunidade de possuírem voz nas negociações em nível multilateral. Deste modo, os Estados assumem laços mais institucionalizados com parceiros mais fortes como uma tática que os permite lucro e evita com que se tornem subjugados (Grieco, 1995, p. 33-34). Todavia, estes Estados, inclusive a Venezuela, ao ingressarem em arranjos regionais, vão perdendo gradualmente sua plena liberdade de ação devido às restrições legais das instituições. Mesmo que não usufruam de sua liberdade de ação em plena potência, os Estados dão preferencia às instituições, uma vez que estas oferecem uma maior oportunidade de voz e a participação nos lucros advindos do processo regional (Keohane, 1984).

A UNASUL é organização intergovernamental, sem pretensões supranacionais. Assim sendo, podemos notar que tal instituição não infringe a autonomia brasileira ao passo que permite angariar apoio de Estados-membros menores. A partir desta afirmação podemos inferir que o Brasil induz tais Estados a agirem de maneira a alcançar objetivos, brasileiros e seus próprios, deste modo nota-se uma equiparação de metas (Destradi, 2008). Apesar desta homogeneização de objetivos, podemos distinguir dois programas distintos para a região sul-americana. De um lado temos a Venezuela de Hugo Chávez com uma veia geoestratégica e militar, ao passo que do outro temos o Brasil com um projeto pautado no desenvolvimento econômico (Serbin, 2009, p. 145). Percebe-se que a liderança brasileira nas iniciativas de integração para as Américas não é percebida apenas 
pelos benefícios obtidos na região, mas também pelas aspirações mais robustas, aspirações à liderança regional (Wade, 2010, p. 43). Devido a essas pretensões de liderança, a República Federativa do Brasil procura inserir a Venezuela em arranjos institucionais como uma maneira de racionalizar poder e conter seu projeto divergente.

Ao aplicarmos tanto Grieco quanto Gruber ao entorno regional, notamos como que na tentativa de racionalizar poder, o Brasil conforma a Venezuela em instituições altamente vinculantes, mantendo-a em sua posição defensiva e contribuindo para uma ampliação de sua segurança (Grieco, 1999). Por consequência, os esforços se traduzem na criação de práticas regionais que limitam o escopo do processo político e evitam que atitudes bem como práticas ameaçadoras ao projeto regional brasileiro venham à tona (Gruber, 2005, p. 102-104).

Como dito anteriormente em âmbito do MERCOSUL, uma das formas encontradas pelo Brasil para conter a Venezuela foi à postulação de um Protocolo Adicional ao Tratado Constitutivo da UNASUL sobre compromisso com a democracia (2010). Tal protocolo estabelece a plena vigência das instituições democráticas e respeito irrestrito aos direitos humanos. O supracitado estipula a aplicação de sanções punitivas àqueles que romperem com os padrões democráticos previstos em texto jurídico constitutivo. Desta forma, podemos notar como o Brasil vem conformando a Venezuela em um arranjo que a priva da plena liberdade de ação, além de avançar temas na agenda que são de interesses brasileiros, mas que aos poucos vão sendo entendidos como temas do interesse dos membros de tal instituição.

Contudo, a opção venezuelana de integrar os arranjos regionais pode ser entendida tanto como parte de seu projeto regional de liderança, exercendo influência em outros atores, como também uma forma de racionalizar o exercício do seu poder (Serbin, 2009). 
Mas além disso, também podemos entender tal inserção através do argumento de Grieco de que as instituições podem ser entendidas como plataformas de projeção de poder e racionalização do mesmo (Grieco, 1996).

\section{Comunidade dos Estados Latino Americanos e o Caribenhos (CELAC)}

A criação de um mecanismo de integração regional entre a América Latina e o Caribe, não é algo recente e inusitado, existiam já projetos prévios que identificavam a urgente necessidade de um veiculo de integração, mais abrangente, que não só priorizava aspectos econômicos e comercias como na CALC (Cúpula da America Latina e do Caribe), nem apenas um fórum de concentração política que visava estabilizar politicamente os países latino-americanos, como no Grupo do Rio (Aravena, 2012, p. 16).

A Cúpula da América Latina e do Caribe surge como um afunilamento dos laços econômicos e políticos dos países da região. Em sua primeira conferência (1998), a já mencionada tinha objetivos principalmente em âmbito econômico visto que se buscava a formalização de acordos comerciais intra-regionais, preocupação e monitoramento com relação aos reflexos das crises financeiras. A segunda reunião da CALC (1999) traz a aprovação do Plano de Ação Montego Bay. O supracitado amplia a cooperação entre os mecanismos regionais e sub-regionais de integração, tornando-os mais robustos, e propõem uma vasta agenda a ser implementada. Tal agenda é incorporada no processo de constituição da CELAC e deve ser de fato posta em prática na supracitada.

O Grupo do Rio (1986) foi uma iniciativa de importante papel nos processos de estabilização política em meio aos países da América Latina. Era composto por todos os países da América do Sul (a exceção da Guiana Francesa) e por países da América Central, sendo que estes possuíam participação rotativa em meio ao grupo. O grande 
propósito deste mecanismo era a cooperação através da concertação, possuía alto grau de institucionalização e flexibilidade. Abordava além de temas políticos, sociais, direitos e de caráter mais estratégicos (Borges, 2001, p. 60-62).

Apesar de ser uma instituição diferente das anteriores, e de ter novos propósitos, a CELAC herda o patrimônio intelectual, e mais ainda, herda da CALC e do Grupo do Rio os compromissos assumidos previamente perante outros fóruns internacionais. Adicionando os a seu principal propósito de criar um mecanismo de convergência, sem que as diferenças entre seus membros tornem se um empecilho (Aravena, 2012, p. 1617). Dentre as diferenças entre os Estados-membros, nota-se, a disparidade de objetivos, onde países como a Venezuela, onde ao entrar em tais arranjos, buscam uma maior "voz", de forma a alterar sua posição relativa no sistema. Tal busca afeta o Estado brasileiro, que por sua vez, estimula o ingresso da mesma em instituições como a CELAC, como uma forma de racionalizar poder, restringindo a atuação desta e de suas pretensões ameaçadoras ao Brasil.

A criação da CELAC, só aconteceu graças aos esforços conjuntos dos principais atores regionais: Brasil e México, e esta representa o esforço de integração da America Latina, aliado a uma vontade política de que haja um novo regionalismo sem deixar que dificuldades de lidar com as diversidades entre os Estados atrapalhe o desenvolvimento da organização (Aravena, 2012, p. 16).

Os principais pontos da CELAC são: estabelecimento de dialogo político intergovernamental (perpassando por inúmeras áreas, como a econômica, social, cultural, entre outras). A criação de uma estratégia energética sul-americana, que traz integração em termos de infraestrutura energética bem como na área de energia dos biocombustíveis. A melhoria da infraestrutura de transportes e de telecomunicação, entre outros. 
Para corroborar com a hipótese que pretendemos testar, há um esforço de traçar uma estratégia energética sul-americana por parte do Brasil, que busca criar um mercado internacional para os biocombustíveis fazendo destes comodities. Ao buscar este objetivo, o Brasil, busca na verdade, racionalizar o poder venezuelano, país que tem como base de sua política externa sua comoditie mais valiosa: o petróleo. Ao criar uma alternativa “sustentável” a este, o país líder no sistema regional, Brasil, mina as pretensões ameaçadoras da Venezuela de tentativa de alteração da sua posição relativa em meio ao sistema, mantendo-a sob seu controle. Ao reduzir a influência do pilar da política externa venezuelana, o petróleo, na América Central, o Brasil diminui atuação bolivariana na mesma e abre espaço para sua projeção de poder (Grieco, 1997).

Assim como no MERCOSUL e na UNASUL, a CELAC é dotada de cláusula democrática, postulada na Declaração Especial sobre a Defesa da Democracia e a Ordem Constitucional na CELAC (2011). Podemos considerar a cláusula como necessária, uma vez que, desde os anos 2000, o consenso sobre a importância dos regimes democráticos vem perdendo peso em países em desenvolvimento, sendo estes substituídos por modelos nacionalistas orientados por padrões diferentes de democracia (Saraiva e Ruiz, 2009, p. 151). Tal declaração reitera o respeito máximo e irrestrito ao estado de direito, a soberania e à integridade territorial, à defesa da democracia e a proteção dos Direitos Humanos e liberdades fundamentais. Estes são pré-requisitos essenciais para a participação de um Estado na CELAC e seus diferentes órgãos, não sendo admitidos retrocesso e desrespeito de nenhum deles. Como visto em âmbito do MERCOSUL e UNASUL, na CELAC também se percebe a intenção do Brasil em conformar a Venezuela em uma amarra que a limita de ter plena potência de sua atuação. 


\section{Conclusão}

Em síntese, tornou-se evidente Mediante os elementos expostos, concluímos que, de fato, o Brasil faz uso de sua relevante participação nos recentes processos de integração na América Latina para projetar sua imagem de liderança política em nível regional e para manter sua posição defensiva em meio ao sistema regional. Para tal, comedir as ações venezuelanas de ampliação de poder, regradas em numa política de esquerda radical e agressiva, é uma condição necessária. Dessa forma, o Brasil vem empreendendo essa política de maneira velada, com o respaldo das instituições internacionais analisadas, MERCOSUL, UNASUL e CELAC.

Confere-se, então, que a hipótese proposta é confirmada. As abordagens dos autores utilizados, Félix Arellano, Sean Burges e Míriam Saraiva, somadas ao embasamento teórico de Joseph Grieco e Lloyd Gruber, se complementam, corroborando a ideia analisada de que o Brasil é assaz favorável à adesão às instituições regionais por parte da Venezuela, devido à necessidade de restringir as ações da mesma, refreando, assim, a possível ameaça à sua posição relativamente superior no sistema. Nesse sentido, os arranjos regionais apresentam-se extremamente úteis aos propósitos brasileiros.

Pode-se observar que, com a fomentação do MERCOSUL, o Brasil tem sua participação mais ativa e destacada em meio ao sistema regional e uma clara construção de sua imagem de liderança, ainda que sem pretensões hegemônicas. Este papel já era previamente abalizado em face as dimensões continentais e sua forte economia correspondente a tal consideração. O MERCOSUL acaba por ser a cristalização do êxito da política externa comercialista brasileira (Arellano, 2009, p. 127), além de garantir a estabilidade e previsibilidade pretendidas. 
No âmbito político e militar, com a manutenção dos Estados sul-americanos na UNASUL, o Brasil reforça sua posição favorável e destaca a realização de seus interesses no escopo da instituição. Apoiado na legitimidade jurídica do arranjo, o Brasil consegue, ainda, limitar a capacidade de ação venezuelana, uma vez que a instituição reforça os padrões democráticos. Ao inserir a Venezuela em arranjos desse tipo, o Brasil acaba distanciando-a de seu programa político agressivo, racionalizando o poder da mesma e, portanto, promovendo sua própria segurança.

As dissonâncias entre as políticas externas dos dois Estados têm sido o principal motor dessa disputa velada. Ambos os Estados buscam uma maior projeção de seu poder regional, gerando uma tensão entre seus governos. No entanto, o Brasil opta por políticas caracterizadas pela tentativa de contornar a tensão, isto é, através da cooperação e integração regional, promovendo uma limitação, legitimada por essas instituições analisadas, da liberdade de ação venezuelana.

Ao estimular cada vez mais a entrada da Venezuela nesses arranjos institucionais de caráter altamente vinculante, o Brasil, gradualmente, garante sua consolidação como líder regional, uma vez que os demais Estados da região oferecem pouco ou nenhum risco à posição brasileira dentro do sistema, uma vez que não executam políticas agressivas e/ou de expansão como as empreendidas pela Venezuela. Logo, verifica-se o desejo brasileiro de fazer frente à economia energética da mesma, trazendo alternativas ao petróleo e projetando seu poder. Ao conformar a Venezuela em arranjos como a CELAC e desenvolver alternativas ditas "melhores" (sustentáveis) ao seu principal mecanismo de política externa, o Brasil busca, mais uma vez, reduz a influência venezuelana no sistema e estreita sua possibilidade de alavancar sua posição no sistema, reduzindo, assim, às 
ameaças à sua própria posição, uma vez considerando o petróleo como o grande elemento da política externa venezuelana.

De tal modo, toma-se conta de que o Brasil faz uso do corpo das instituições para reduzir a capacidade de ação da Venezuela, atingindo-a nos pontos essenciais à sua tentativa de projetar poder. Isso se confirma no que tange à redução das barreiras alfandegárias proposta pelo MERCOSUL, que acaba favorecendo o Brasil, uma vez que isso funciona como mecanismo de negociação e a economia venezuelana depende muito das exportações para o Brasil, enquanto o oposto não se verifica. Além de tal dependência comercial, os arranjos vinculam a Venezuela a alguns compromissos que vão de encontro ao seu intento de projeção de poder, como na UNASUL, que reforça a democracia e promove sanções ao descumprimento da mesma. Tal tentativa de ampliação de poder por parte da Venezuela é, ainda, dificultada, em âmbito da CELAC, pela tentativa brasileira de incorporar uma estratégia energética sustentável, fazendo frente ao principal meio de política externa da Venezuela, o petróleo.

A partir disso, conclui-se que a estratégia brasileira de recorrer às formas de cooperação, traduzidas pela conformação em arranjos regionais, não é, portanto, uma evidência de irracionalidade do Estado, pelo contrário, demonstra, aos moldes do neorrealismo defensivo de Grieco, que o Brasil assume uma postura defensiva para manter sua posição relativa superior no sistema, projetando seu poder regional e alçando a si mesmo à condição de líder na região aos olhos do Sistema Internacional. O Estado brasileiro realiza seu intento, contudo, sem recorrer a uma postura agressiva, utilizandose de sua projeção de poder para manipular e constranger as ações venezuelanas de maneira velada, ou seja, sem incorrer em grave risco à própria segurança. 
No decorrer dessa análise, torna-se evidente o motivo pelo qual o Brasil conforma arranjos institucionais como o MERCOSUL, UNASUL e CELAC, deixando clara sua intenção de utilizar esses arranjos como mecanismo defensivo, além de se consolidar como líder regional e sufocar as tentativas venezuelanas de empreender sua própria projeção de poder.

\section{Referências.}

ARAVENA, F. La CELAC e La Integracion Latinoamericana e Caribeña: principales claves e desafios. Nueva Sociedad, julho-agosto de 2012. p. 16-27.

ARELLANO, F. O Brasil e a Venezuela: uma relação perigosa, Nueva Sociedad, p. 121 - 136, dezembro de 2009.

BANDEIRA, L.A.M. Venezuela é Indispensável. Revista Espaço Acadêmico, no 56 , janeiro de 2006. Disponível em: <http://espacoacademico.com.br/056/56bandeira.htm>. Acesso realizado dia 20 de maio de 2014.

BORGES, B. Leveza Sob Pressão: Um Estudo sobre poder, instituições e o Grupo do Rio, 2001. Dissertação de Mestrado, Instituto de Relações Internacionais, Pontifícia Universidade Católica do Rio de Janeiro, p. 1-119.

BURGES, S. Building a global Southern coalition: the competing approaches of Brazil's Lula and Venezuela's Chavez. Third World Quarterly, v. 28, nº 7, p. 1343 1358, 2007.

BRICENO-RUIZ \& VASQUEZ. O MERCOSUL na época de Lula e Kirchner: um balanço, seis anos depois. Nueva Sociedad, n. 214, Março-Abril, p. 33 - 48, 2008.

CEBRI. A Questão Jurídica da Suspensão do Paraguai no Mercosul. CEBRI, v.4, ano VII, p.8 - 34, 2012.

DESTRADI, S. Empire, Hegemony, and Leadership: Developing a Research Framework for the Study of Regional Powers. GIGA German Institute of Global and Area Studies. Hamburg, Germany. No. 79, p. 5 - 30, 2008.

FLEMES, D. Brazil's Strategic Options in a Multiregional World Order. GIGA German Institute of Global and Area Studies. Hamburg, Germany, 15-16 Sept. 2008.

GEHRE, T. Uma história de parceria: as relações entre Brasil e Venezuela (1810-2012). Belo Horizonte, Fino Traço, 2012. 
GRUBER, L. Power politics and the institutionalization of international relations. In Power in Global Governance, Cambridge University Press, 2005. p.102-129.

GRIECO, J. The Maastricht Treaty, Economic and Monetary and the New-realist Research Program. Review of International Studies, vol.21, n¹, Janeiro 1996. p.21-40.

Realist International Theory and the Study of World Politics. In_ New Thinking in International Relations Theory, 1997. p.163-197.

ITAMARATY. Celac. Itamaraty, 2014. Disponível em: <http://www.itamaraty.gov.br/temas/america-do-sul-e-integracao-regional/celac $>$.

Acesso realizado dia 19 de maio de 2014.

MERCOSUL. Itamaraty, 2014. Disponível em: <http://www.itamaraty.gov.br/temas/america-do-sul-e-integracao-regional/mercosul >. Acesso realizado dia 20 de maio de 2014.

KEOHANE, R. O. After Hegemony: Cooperation and Discord in the World Political Economy. Princeton: Princeton University Press, 1984.

MARCHIORI, A.P. A Comunidade Sul-Americana das Nações: Um projeto de integração. In_ Integração Sul-americana: desafios e perspectivas, Porto Velho, 2011. p. 146-181.

MARTIN. L. Interests, power and multilateralismo. International Organization. v. 46, n.4, p. 765-792, Outono 1992.

MEARSheIMER, J. J. The Tragedy of Great Power Politics. Nova York: W.W. Norton \& Company, 2001.

SARAIVA, M. Brazilian foreign policy towards South America during the Lula Administration: caught between South America and Mercosur, 2010. p. 151-168.

SARAIVA \& RUIZ. Argentina, Brasil e Venezuela: as diferentes percepções sobre a construção do MERCOSUL, 2009. p. 149-176.

SERBIN, A. América del Sur en un mundo multipolar: ¿es la Unasur la alternativa?, Nueva Sociedad, n 214, Março-Abril 2008. p. 145-156.

VAZ, A.L. La Comunidad de Estados Latinoamericanos y Caribeños, Nueva Sociedad, n. 227, Maio-Junho de 2010, p. 4 - 8.

VIGEVANI, T,; RAMANZINI JUNIOR, H. The Grounding of Regional Integration for Brazil: Universalism, Sovereignty and Elite Perception. Global Society. V. 25, n.4, p. $450-468,2011$. 
WADE, A. The Union of South American Nations ("UNARSUR"): Challenges and Opportunities for States Pursuing Regional Integration, Tese de Mestrado, George Washington University, 2010.

WALTZ, K. Theory of International Politics. Reading, Massachusetts: Addison-Wesley Publishing Company, 1979. 